\title{
Estimating Catastrophic Health Expenditures from Household Surveys: Evidence from Living Standard Measurement Surveys (LSMS)-Integrated Surveys on Agriculture (ISA) from Sub-Saharan Africa
}

\author{
Sarah Ssewanyana ${ }^{1} \cdot$ Ibrahim Kasirye ${ }^{1}$
}

Published online: 10 September 2020

(c) The Author(s) 2020

\begin{abstract}
Background Out of pocket (OOP) payments for healthcare remain a significant health financing challenge in sub-Saharan Africa (SSA). Understanding the drivers and impacts of this financial health burden is both an economic and a public health priority.

Objective This study examines how the burden of OOP health expenditures varies with different thresholds for financial catastrophe.

Methods The analysis is based on Livings Standards Measurement Surveys (LSMS)-Integrated Surveys on Agriculture (ISA) for five SSA countries-Ethiopia, Malawi, Nigeria, Tanzania, and Uganda. We estimate the degree by which OOP payments as share of total household non-food expenditures exceed either the 15 or $25 \%$ threshold.

Results For the countries considered, the severity of OOP payments is substantial-the average positive overshoot (beyond the $25 \%$ threshold) is above $10 \%$, except for Nigeria. This reflects a higher percentage of OOP in total household health expenditures-compared to taxes and contributions-especially among the poor in these specific countries. Regarding sensitivity of distribution of catastrophic health expenditures, we find that households with low non-food expenditures are more likely to incur catastrophic payments with the exception for Uganda where catastrophic payments increase with the increase of non-food household expenditures.

Conclusion The burden of catastrophic health expenditures remains large. In order to reduce this burden, public health expenditures need to be expanded as an alternative. This calls for renewed attention to expand public revenues as the most sustainable methods of financing health expenditures in Africa.
\end{abstract}

Ibrahim Kasirye

ikasirye@eprcug.org

Sarah Ssewanyana

Ssewanyana@eprcug.org

1 Economic Policy Research Centre (EPRC), Makerere

University, Kampala, Uganda

\section{Key Points for Decision Makers}

The burden of catastrophic health expenditures remains large in sub-Saharan Africa.

To reduce this burden, public health expenditures need to be expanded as an alternative.

Public revenues are the most sustainable option for financing health expenditures in Africa, given the level of deprivation on the sub-region. 
Table 1 Health spending in selected African countries in 2015. Source: [10]

\begin{tabular}{|c|c|c|c|c|c|}
\hline & \multicolumn{5}{|c|}{ Distribution of major expenditure category as a share of total health spending } \\
\hline & $\begin{array}{l}\text { Total health expenditure } \\
\text { as share of GDP }(\%)\end{array}$ & $\begin{array}{l}\text { Domestic pub- } \\
\text { lic health }(\%)\end{array}$ & $\begin{array}{l}\text { Health } \\
\text { insurance } \\
(\%)\end{array}$ & $\begin{array}{l}\text { Out of } \\
\text { pocket } \\
(\%)\end{array}$ & $\begin{array}{l}\text { Development } \\
\text { assistance (\%) }\end{array}$ \\
\hline Ethiopia & 4.1 & 33.2 & 2.6 & 37.8 & 26.4 \\
\hline Malawi & 9.3 & 47.3 & 3.4 & 10.9 & 38.4 \\
\hline Nigeria & 3.7 & 18.2 & 8.6 & 72.1 & 1.1 \\
\hline Tanzania & 6.1 & 40.1 & 8.8 & 26.2 & 24.9 \\
\hline Uganda & 7.3 & 27.9 & 2.4 & 40.5 & 29.2 \\
\hline Sub-Saharan Africa & 6.2 & 41.7 & 11.1 & 35.3 & 11.9 \\
\hline Global & 8.3 & 59.2 & 17.4 & 22.8 & 0.6 \\
\hline
\end{tabular}

$G D P$ gross domestic product

\section{Introduction}

Catastrophic health expenditures remain a significant health financing challenge in sub-Saharan Africa (SSA) and understanding the drivers and impacts of this financial health burden is both an economic and a public health priority. ${ }^{1}$ Estimates by World Health Organization and World Bank [2] show that globally 179 million people (2.6\% of the population) incurred catastrophic payments in 2010 exceeding $25 \%$ of total income or consumption. Furthermore, whereas per capita health spending in SSA increased at an annualized rate of 3.2\% during 1995-2014 period [3], on average 36\% of the health expenditures in the region are made through out of pocket (OOP) compared to only $22 \%$ for rest of the world [4]. In addition, catastrophic health expenditures have varied widely within SSA-ranging from a very low $1 \%$ in Botswana to a high of $25 \%$ in Nigeria [1].

Out of pocket (OOP) health expenditures affect households differently depending on whether savings or consumption is used to finance such expenditures. Reduction in consumption to finance health expenditures can be impoverishing if it leads or pushes households further into poverty [2]. In addition, the potential risk of impoverishment may lead to changes in health seek behaviour. Due to unaffordable services, some vulnerable groups may avoid seeking the required health services [5, 6]. Furthermore, there is evidence to show that financing healthcare using OOP payments disproportionally affects poorer households in Ghana, South Africa and Tanzania [7]. Previous studies also show that the share of households spending more than $5 \%$ of income on health varies widely in SSA-ranging from $11 \%$ in Ghana [8] to $39 \%$ in Nigeria [9]. Given that OOP can lead to inequalities, this study contributes to the literature

\footnotetext{
${ }^{1}$ According to [1], catastrophic health expenditures are out of pocket payments that exceed a certain threshold e.g. $25 \%$ of a household's non-subsistence income or non-food expenditures.
}

by examining how the incidence of catastrophic payments differ in countries with different sources of health spending in SSA. Specifically, we examine the following policy question "How much does the burden of OOP payments exceed the threshold for financial catastrophe?"

\subsection{Selected SSA Countries}

The study uses the Livings Standards Measurement Surveys (LSMS)-Integrated Surveys on Agriculture (ISA) for five SSA countries-Ethiopia, Malawi, Nigeria, Tanzania, and Uganda. The choice of the five countries is guided both by the availability of comparable data and the variation in the health system financing in the selected countries. Table 1 shows that there are wide variations in the way the 5 selected countries finance their health systems. While Ethiopia's total health expenditure as share of the gross domestic product (GDP) is only $4.1 \%$, OOP payment accounts for the bulk of health expenditures in the country at $38 \%$. On the other hand, at $9.3 \%$ of GDP, Malawi allocates a substantial share of its resources to health-substantially higher than the SSA average of $6.2 \%$. However, a large proportion of the Malawi health resources are contributed by development partners-38\%. Furthermore, health insurance coverage in Malawi is extremely low at less than 5\%, and those covered by the employer-based insurance are mainly individuals who have attained post-secondary education [11].

Table 1 also shows that Nigeria spends only $3.7 \%$ of its GDP on health-the lowest level for all the five countries considered. Indeed, partly due to the lower public spending on health, at least $72 \%$ of the total health expenditures in Nigeria are met through OOP payments. As such, the country carries a high risk of catastrophic health expenditures. Since 1999, the country has operated a National Health Insurance Scheme. However, less than $10 \%$ of the population is covered by health insurance, predominantly employer-based insurance [12]. Health facilities in Nigeria 
Fig. 1 Proportion of individuals who do not seek health care when sick by welfare status (\%). Source: Authors calculations from LSMS-ISA surveys for Ethiopia, Nigeria, Uganda and Malawi. No information was collected in Tanzania regarding whether a sick individual did not seek health
Gotton quintile $\cong$ Richest Quintile
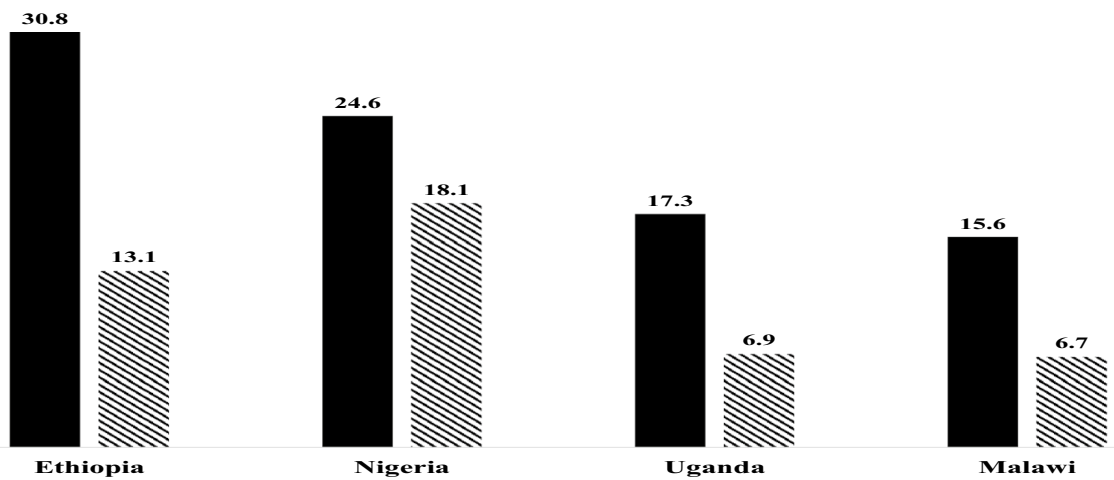

charge user fees with a few exemptions for antenatal services piloted in selected states.

At $6.1 \%$ of GDP, Tanzania allocates a relatively large share of its resources to healthcare expenditures. Tanzania introduced user fees in public health facilities in 1994 with exemptions for some illnesses and demographic groups (children aged $<5$ years and adults aged $>60$ years). Since 2001, the country has operated a National Health Insurance Fund (NHIF), which is funded by mandatory contributions from formal sector employees and voluntary contributions for informal sector workers. At least $9 \%$ of adults in Tanzania are covered by health insurance, mainly communitybased mutual insurance [13]. On the other hand, most of the health expenditures in Uganda are met privately (Table 1) while $<6 \%$ of adults are covered by health insurance [14].

Despite the above healthcare expenditures, a substantial proportion of individuals who fall sick may fail to access health services. Estimates based on the LSMS-ISA survey ${ }^{2}$ indicate that Ethiopia and Nigeria have the largest proportion of individuals who have not consulted a healthcare provider for illness during the past month $-22 \%$ and $21 \%$, respectively. Figure 1 shows that in Ethiopia, individuals from the poorest quintile are disproportionally less likely to seek health services than those in the richest quintile (31 vs $13 \%)$. On the other hand, differences between the poorest and richest quintiles in Nigeria are less pronounced.

\section{Methods}

\subsection{Data}

We utilise data from the LSMS-ISA surveys. These are part of a global programme supported by the World Bank to undertake panel surveys and are conducted by national

\footnotetext{
${ }^{2}$ No information was collected in Tanzania regarding whether a sick individual did not seek health services.
}

Table 2 LSMS-ISA surveys to be used in the analysis. Source: World Bank

\begin{tabular}{llll}
\hline & Country & Survey year & $\begin{array}{l}\text { Number of } \\
\text { households }\end{array}$ \\
\hline 1 & Ethiopia & 2015 & 4954 \\
2 & Malawi & 2013 & 4000 \\
3 & Nigeria & 2013 & 4536 \\
4 & Tanzania & 2015 & 3344 \\
5 & Uganda & 2015 & 3285 \\
\hline
\end{tabular}

LSMS-ISA Living Standards Measure Study-Integrated Surveys on Agriculture

statistical agencies. ${ }^{3}$ The surveys monitor population, health, and agricultural programmes in developing countries. The surveys are nationally representative and use standardised questionnaires across the different countries. As noted earlier, we use LSMS-ISA surveys from five countries, i.e. Ethiopia, Malawi, Nigeria, Tanzania, and Uganda. All five countries have at least one survey conducted during 2013-2015. The sample size is relatively large, covering more than 3200 households in each survey round. Table 2 shows the coverage of each specific survey used.

All the LSMS-ISA are based on a two-stage cluster sampling design. In the first stage, clusters or enumeration areas (EAs) stratified according to spatial location are the principal sampling unit. The selections of EAs was based on the most recent census as the frame for each country. In the second stage, 10 households are randomly selected from each EA. Each LSMS-ISA survey is composed of at least three questionnaires: the household, agricultural, and community questionnaires. The household questionnaire covers the characteristics of the household, e.g. demographic composition and individual experience of shocks. The household

\footnotetext{
${ }^{3}$ Further details about the conduct of LSMS-ISA surveys can be obtained at http://surveys.worldbank.org/lsms/programs/integrated -surveys-agriculture-ISA.
} 
questionnaires have a detailed health module capturing individual experience of illness during the past 30 days prior to the survey. Information captured in the health module includes the nature of illness, type of healthcare provider sought, and the cost of health services if paid for. In addition, the health module captures distance to healthcare provider. Furthermore, ISA surveys capture at the household level, health and medical care expenditures during the past 30 days. This serves as the major indicator of OOP expenditures used in the analysis. Finally, the ISA surveys also contain a detailed community questionnaire with a health facility survey. The facility survey captures services offered at the facility and their corresponding costs.

\subsection{Estimation Approach}

We utilise the framework by Wagstaff and van Doorslaer [15] who examined catastrophic health expenditures in another developing country (Vietnam). In this model, catastrophic expenditures are measured in relation to either total household expenditure or non-discretionary household expenditures (i.e. after accounting for food expenditures). For the present study, we adopt non-food expenditures as our reference for catastrophic health payments.

Healthcare expenditures are considered as catastrophic if they exceed a given threshold. This is formally represented as

$\mathrm{CTP}=\frac{T}{E-F}>z$,

where CTP is the catastrophic health expenditures, $T$ is OOP expenditures, $E$ is total household expenditures, $F$ are food expenditures and $\mathrm{Z}$ is a set threshold. The incidence of catastrophic health expenditures can be considered within the realm of the standard Foster-Greer-Thorbecke (FGT) class of poverty indexes that incorporate the three most common poverty measures-poverty head count $\left(P_{0}\right)$, poverty gap $\left(P_{1}\right)$, and the square poverty gap $\left(P_{2}\right)$. If we define CTP equal 1 if $\frac{T_{i}}{E_{i}-F_{i}}>1$ land zero otherwise, then the head count measure is defined as

$H=\frac{1}{N} \sum_{i=1}^{N} \mathrm{CTP}_{i}$

The headcount does not reveal the extent to which households exceed a given threshold. To capture the extent to which household exceed the set thresholds, we measure the "catastrophic payment overshoot" and this captures the average degree by which OOP payments as share of total household non-food expenditures exceed the threshold $Z$. The overshoot is formally defined as
$O_{i}=\operatorname{CTP}\left[\left(\frac{T_{i}}{E_{i}-F_{i}}\right)-Z\right]$

where $T_{i}$ represents the OOP payments of household $\mathrm{i}$, $E_{i}-F_{\mathrm{i}}$ represents the household non-food consumption expenditure of household $i$, and $Z$ represents the catastrophic threshold selected. The actual estimates of the overshoot are a simple average of the estimate in Eq. (3) defined as

$O=\frac{1}{N} \sum_{i=1}^{N} O_{i}$

Following [15] as well as [16], the intensity of catastrophic expenditures is estimated as the average of the catastrophic overshoot over all households that exceed the selected catastrophic threshold. The estimated average is referred to as the mean positive overshoot. Formally, this is defined as

$\mathrm{MPO}=\frac{O}{H}$.

It is also important to understand how catastrophic payments affect different households based on the status of the welfare distribution. The distribution of the incidence and intensity of catastrophic payments is assessed by estimating concentration indices $(\mathrm{CI})$ for household overshoot $\left(O_{i}\right)$ and CTP. Following [15], the CIs are estimated using the covariance between the fractional rank of the household sorted by socio-economic status (consumption expenditures) and the variable of interest. If the corresponding CIs for the catastrophic payments and overshoot are labelled $C_{\mathrm{E}}$ and $C_{\mathrm{O}}$ respectively, they can take on values ranging from -1 to +1 . A positive $C_{\mathrm{E}}$ indicates a greater tendency for the relatively well-to-do households to exceed the selected threshold while a negative index indicates that it is mainly the worse off that exceed these payments. Similarly, a positive value for $C_{\mathrm{O}}$ indicates that the overshoots are concentrated among richer households. Following Wagstaff et al. [15], in order to take into account the distribution-sensitive aspects of catastrophic payments, both the headcount and overshoot measures are adjusted by multiplying with the corresponding CI. Formally, this is written as:

$H^{\mathrm{W}}=H\left(1-C_{\mathrm{E}}\right), H_{\mathrm{w}}\left\langle H\right.$ if $\left.C_{\mathrm{e}}\right\rangle 0$

$O^{\mathrm{W}}=O\left(1-C_{o}\right), H_{\mathrm{w}}\left\langle H\right.$ if $\left.C_{\mathrm{o}}\right\rangle 0$

\subsection{Variables Used in the Analysis}

Household health expenditures are payments for direct healthcare services, such as medicines, consultation fees, hospital/clinic charges, laboratory diagnostic tests, as well as 
fees paid to traditional doctors and medicine. These expenditures are obtained from the consumption module of the survey-in particular the section on non-durable goods and frequently purchased services during the last 30 days.

Non-food household expenditures These are total household consumption expenditures less expenditures on food, i.e. housing, durable goods, health, education and transportation. This is derived from the consumption module of the LSMS surveys.

Threshold of catastrophic health expenditures In the literature, various thresholds are used to capture the severity of catastrophic health expenses-ranging from 10 [17] to $40 \%$ [16]. Following World Health Organization and World Bank [2], we adopted the $15 \%$ and $25 \%$ threshold and defined catastrophic health expenditures as health expenditures that are either $15 \%$ or $25 \%$ of a household's ability to pay, where ability to pay is measured by non-food household expenditures.

\section{Results}

\subsection{Extent and Intensity of Catastrophic Expenditures}

Table 3 shows the incidence of catastrophic health payments based on non-food household expenditures. For each country, the table shows the head count and overshoot as well as the corresponding standard errors in addition to the mean overshoot. The overshoot measure captures the severity of catastrophic payments. As mentioned earlier, we examine how the burden of OOP varies between $15 \%$ and our adopted threshold of $25 \%$.

Based on the $25 \%$ threshold, Table 3 shows that catastrophic expenditures vary widely-ranging from $0.84 \%$ in Nigeria to $20.2 \%$ in Tanzania. ${ }^{4}$ Indeed, Tanzania (22.2\%) and Uganda $(8.2 \%)$ lead in having the highest share of households spending in excess of $25 \%$ of their non-food expenditures on healthcare. On the other hand, apart from Nigeria, Malawi is the other country with the lowest level of catastrophic health expenditures (1.57\%). The distribution for the estimates of the overshoot mirror those of the headcount, i.e. ranging from $0.08 \%$ in Nigeria to $4.23 \%$ in Tanzania.

With respect to the intensity of catastrophic payments, Table 3 shows that the mean positive overshoot is remarkably high for some countries-notably Ethiopia, Tanzania, and Uganda-especially at the $25 \%$ threshold of the

\footnotetext{
${ }^{4}$ Previous research by [18] based on the Kagera region in Northern Tanzania points to the high burden of disease due to chronic illness as a major driver for catastrophic health expenditures in the country.
}

Table 3 Incidence and intensity of catastrophic health payments defined with respect to non-food expenditure, different thresholds. Source: Authors calculations from LSMS-ISA surveys

\begin{tabular}{|c|c|c|}
\hline \multirow{2}{*}{$\begin{array}{l}\text { Catastrophic payments measures } \\
\text { Out-of-pocket health spending }\end{array}$} & \multicolumn{2}{|c|}{$\begin{array}{l}\text { Threshold budget share } \\
(z)\end{array}$} \\
\hline & $15 \%$ & $25 \%$ \\
\hline \multicolumn{3}{|l|}{ Malawi } \\
\hline Head count $(\mathrm{H})$ & $4.97 \%$ & $1.57 \%$ \\
\hline Standard error & $0.60 \%$ & $0.31 \%$ \\
\hline Overshoot $(\mathrm{O})$ & $0.52 \%$ & $0.21 \%$ \\
\hline Standard error & $0.08 \%$ & $0.05 \%$ \\
\hline Mean positive overshoot (MPO) & $11.04 \%$ & $13.56 \%$ \\
\hline \multicolumn{3}{|l|}{ Nigeria } \\
\hline Head count $(\mathrm{H})$ & $3.06 \%$ & $0.84 \%$ \\
\hline Standard error & $0.38 \%$ & $0.16 \%$ \\
\hline Overshoot (O) & $0.25 \%$ & $0.08 \%$ \\
\hline Standard error & $0.04 \%$ & $0.02 \%$ \\
\hline Mean positive overshoot (MPO) & $8.10 \%$ & $9.65 \%$ \\
\hline \multicolumn{3}{|l|}{ Ethiopia } \\
\hline Head count $(\mathrm{H})$ & $11.45 \%$ & $5.70 \%$ \\
\hline Standard error & $0.85 \%$ & $0.52 \%$ \\
\hline Overshoot $(\mathrm{O})$ & $1.75 \%$ & $0.94 \%$ \\
\hline Standard error & $0.16 \%$ & $0.11 \%$ \\
\hline Mean positive overshoot (MPO) & $15.32 \%$ & $16.44 \%$ \\
\hline \multicolumn{3}{|l|}{ Tanzania } \\
\hline Head count $(\mathrm{H})$ & $32.24 \%$ & $20.22 \%$ \\
\hline Standard error & $1.16 \%$ & $0.96 \%$ \\
\hline Overshoot $(\mathrm{O})$ & $6.78 \%$ & $4.23 \%$ \\
\hline Standard error & $0.38 \%$ & $0.29 \%$ \\
\hline Mean positive overshoot (MPO) & $21.02 \%$ & $20.91 \%$ \\
\hline \multicolumn{3}{|l|}{ Uganda } \\
\hline Head count $(\mathrm{H})$ & $15.63 \%$ & $8.21 \%$ \\
\hline Standard error & $0.80 \%$ & $0.55 \%$ \\
\hline Overshoot $(\mathrm{O})$ & $2.40 \%$ & $1.27 \%$ \\
\hline Standard error & $0.17 \%$ & $0.12 \%$ \\
\hline Mean positive overshoot (MPO) & $15.37 \%$ & $15.46 \%$ \\
\hline
\end{tabular}

LSMS-ISA Living Standards Measure Study-Integrated Surveys on Agriculture

non-food budgets. Specifically, among those spending more than $25 \%$ of their non-food expenditure on OOP payments, the average OOP budget share exceeded this by 15 percentage points in Uganda, 21 percentage points in Tanzania, and 16 percentage points in Ethiopia.

\subsection{Inequality in Catastrophic Expenditures}

Table 4 examines whether the poorest are more likely to fall into catastrophic payments by estimating distributionsensitive measures of catastrophic payments using concentration indices. The positive indices indicate that the catastrophic expenditures are made mainly by the rich while 
Table 4 Are the poorest more likely to fall into catastrophic health payments? (defined with respect to non-food expenditure), different thresholds. Source: Authors calculations from LSMS-ISA surveys

\begin{tabular}{|c|c|c|}
\hline \multirow{2}{*}{$\begin{array}{l}\text { Catastrophic payments measures } \\
\text { Out-of-pocket health spending }\end{array}$} & \multicolumn{2}{|c|}{ Threshold budget share $(z)$} \\
\hline & $15 \%$ & $25 \%$ \\
\hline \multicolumn{3}{|l|}{ Malawi } \\
\hline Concentration index & -0.1006 & -0.0104 \\
\hline Rank weighted headcount & $5.47 \%$ & $1.59 \%$ \\
\hline Concentration index & -0.0177 & 0.0784 \\
\hline Rank weighted overshoot & $0.53 \%$ & $0.20 \%$ \\
\hline \multicolumn{3}{|l|}{ Nigeria } \\
\hline Concentration index & -0.2884 & -0.3863 \\
\hline Rank weighted headcount & $3.94 \%$ & $1.16 \%$ \\
\hline Concentration index & -0.3158 & -0.2891 \\
\hline Rank weighted overshoot & $0.33 \%$ & $0.10 \%$ \\
\hline \multicolumn{3}{|l|}{ Ethiopia } \\
\hline Concentration index & -0.0508 & -0.0496 \\
\hline Rank weighted headcount & $12.17 \%$ & $6.13 \%$ \\
\hline Concentration index & -0.0198 & -0.0142 \\
\hline Rank weighted overshoot & $1.79 \%$ & $0.95 \%$ \\
\hline \multicolumn{3}{|l|}{ Tanzania } \\
\hline Concentration Index & -0.0450 & -0.1004 \\
\hline Rank weighted headcount & $33.79 \%$ & $22.36 \%$ \\
\hline Concentration Index & -0.0811 & -0.0870 \\
\hline Rank weighted overshoot & $7.33 \%$ & $4.59 \%$ \\
\hline Mean positive overshoot (MPO) & $21.02 \%$ & $20.91 \%$ \\
\hline \multicolumn{3}{|l|}{ Uganda } \\
\hline Concentration index & 0.0506 & 0.0612 \\
\hline Rank weighted headcount & $14.83 \%$ & $7.70 \%$ \\
\hline Concentration index & 0.0953 & 0.1335 \\
\hline Rank weighted overshoot & $2.17 \%$ & $1.10 \%$ \\
\hline
\end{tabular}

LSMS-ISA Living Standards Measure Study-Integrated Surveys on Agriculture

negative measures indicate that it is mainly the poor making catastrophic expenditures. Table 4 shows that CIs are predominantly negative, with one exception for Uganda. For Ethiopia, Malawi, Nigeria, and Tanzania, the results indicate that the households with low non-food expenditures are more likely to incur catastrophic payments. Specifically, for Malawi, at lower thresholds, i.e. below $15 \%$ it is the poor making the excessive expenditures while for the $25 \%$ threshold, it is mainly the rich making the expenditures. For Nigeria, regardless of threshold, it is the poor that make catastrophic expenditures. For Ethiopia, at both the 15\% and $25 \%$ thresholds, it is the poor making the expenditures. Similarly, in Tanzania, the poor make most payments. On the other hand, Uganda's measures are all positive indicating that the burden of catastrophic expenditures is borne by the rich.

\section{Discussion and Conclusions}

This study analyses the incidence and intensity of catastrophic health payment in five SSA countries. Generally, the results reflect the extent of private payment for healthcare in the respective countries. Although, healthcare payments in Nigeria are predominantly made OOP (i.e. $72 \%$ ), households in Nigeria face more pressing expenditures other than health. ${ }^{5}$ On the other hand, in Malawi, as the threshold is increases from 15 to $25 \%$, the estimate for the incidence of catastrophic payments reduces from 4.9 to $1.6 \%$ and the mean overshoot drops from 0.52 to $0.21 \%$ of non-food expenditures. These results suggest that fewer households in Malawi make any healthcare expenditures overall. The low levels of catastrophic expenditures for Malawi is consistent with the context that catastrophic health expenditures are generally low in countries where OOP spending is less than $20 \%$ of total health expenses (OPP contributes only $11 \%$ of health expenses in Malawi (Table 1).

Furthermore, our empirical results show that the share of the population facing catastrophic health expenditures, based on the $25 \%$ threshold, varies from an extremely low $0.84 \%$ in Nigeria to higher rates of $22.2 \%$ in Tanzania. The counter-intuitive results for Nigeria may be partly explained by dominance of non-health expenditures in the household's non-food budgets and the higher tendency to self-medicate using pharmacies and chemists. Our results also indicate that it is mainly the relatively poor individuals that make catastrophic payments. This suggests that it is primarily the poor that are excluded from the available safety nets such as accessing publicly subsidised health insurance or receiving exclusions from making co-payments. These results have implications for the ability of African countries to achieve SDG 3, especially targets relating to universal health coverage (UHC), including financial risk protection.

The high share of catastrophic expenditures found for Tanzania and Uganda are not unprecedented. Indeed, Brinda et al. [19] find similarly high rates for Tanzania based on 2008/9 survey while Ataguba [20] shows that $17 \%$ of households in Nigeria exceed the $40 \%$ threshold based on a 2003/4 survey. Also, higher estimates have been registered in other African countries, e.g. Lu et al. [21] for Rwanda and Masiye et al. [22] for Zambia. The high share of OOP payments suggests that even in countries like Tanzania with relatively high health insurance coverage, a substantial proportion of the population is not protected from catastrophic expenses. The higher rates in Tanzania may be partly explained by the fact that public

\footnotetext{
${ }^{5}$ Specifically, items such as rent, utilities, transportation and education account for a much larger share of Nigerian household budgets compared to health.
} 
health facilities in the country charge user fees. Furthermore, the fact that the country with the highest health insurance coverage rate (Tanzania) also has the highest rate of catastrophic payments, highlights the challenges of reaching the majority who are informal sector workers, especially those with incredibly low education attainment. This, coupled with the fact that user fees exist for certain demographic groups, implies that countries with no universal health insurance coverage but charging user fees do not offer adequate financial protection. As earlier noted, other countries such as Namibia and Liberia show that health insurance is associated with higher OPP expenses [23].

Relatedly, Uganda is the country with the second highest rate of catastrophic expenditures despite abolishing user fees in 2001. For Uganda, the estimated rate of catastrophic payment of $8.2 \%$, based on 2016 data, is higher than rate recorded based on 2003 data of $2.9 \%$ [6]. This suggests that abolition of user fees only may not be enough to protect citizens from catastrophic expenses. The results for the distribution-sensitive measures are in line with previous studies such as Mills et al. [7] that show that the poor bear the heaviest burden of catastrophic payments.

Overall, in the current setting characterised by low health insurance coverage, the burden of catastrophic health expenditures remains large. In order to reduce this burden, public health expenditures need to be expanded as an alternative. This calls for renewed attention to expand public revenues as the most sustainable methods of financing health expenditures in Africa.

\subsection{Limitations}

The study is not without limitations. The datasets used were for the period 2013-2015. Indeed, the study does not consider the recent changes in the health financing landscape in Africa due to 2014-2016 Ebola outbreak and the 2020 COVID-19 pandemic. It is possible that the health financing situation in the considered countries may have changed significantly by 2020 . Second, the five countries considered may not be representative of sub-Saharan Africa, but nonetheless these countries capture the diversity in sources of healthcare financing on the continent.

Author contributions Sarah Ssewanyana and Ibrahim Kasirye conceived the presented idea. Both authors developed the theoretical framework and performed the computations together, discussed the results, and contributed equally to the final version of the manuscript.

Data Availability Statement The datasets used in this study are publicly available from the Living Standards Measurement (LSMS) web site: http://microdata.worldbank.org/index.php/catalog/lsms.

\section{Declarations}

Conflict of interest The funders were not involved in the study design, data collection or analysis. The decision to publish and the preparation of the manuscript were only the authors' own will. All authors (Sarah Ssewanyana and Ibrahim Kasirye) report no conflicts of interest relevant to this article.

Funding This study was funded by the African Economic Research Consortium (AERC) under the AERC collaborative project on "Healthcare Financing in Africa", Grant No RC17504.

Ethics approval, Consent to participate, Consent for publication, Code availability Not applicable.

Open Access This article is licensed under a Creative Commons Attribution-NonCommercial 4.0 International License, which permits any non-commercial use, sharing, adaptation, distribution and reproduction in any medium or format, as long as you give appropriate credit to the original author(s) and the source, provide a link to the Creative Commons licence, and indicate if changes were made. The images or other third party material in this article are included in the article's Creative Commons licence, unless indicated otherwise in a credit line to the material. If material is not included in the article's Creative Commons licence and your intended use is not permitted by statutory regulation or exceeds the permitted use, you will need to obtain permission directly from the copyright holder. To view a copy of this licence, visit http://creativecommons.org/licenses/by-nc/4.0/.

\section{References}

1. World Health Organization and World Bank. World Health Report 2005: making every mother and child count. Geneva: World Health Organization; 2005.

2. World Health Organization and World Bank. Tracking universal health coverage: 2017 global monitoring report. Geneva: World Health Organization; 2017.

3. Global Burden of Disease Health Financing Collaborator Network. Evolution and patterns of global health financing 19952014: development assistance for health, and government, prepaid private, and out-of-pocket health spending in 184 countries. Lancet. 2017;389:1981-2004.

4. McIntyre D, Obse AG, Barasa EW, Ataguba JE. Challenges in financing universal health coverage in Sub-Saharan Africa. Oxford: Oxford Research Encyclopedia of Economics and Financ; 2018.

5. Russell S. The economic burden of illness for households in developing countries: A review of studies focusing on malaria, tuberculosis, and human immunodeficiency Virus/acquired immunodeficiency syndrome. Am J Trop Med Hyg. 2004;71(Supp. 2):147-55.

6. Xu K, Evans DB, Kadama P, et al. Understanding the impact of eliminating user fees: utilization and catastrophic health expenditures in Uganda. Soc Sci Med. 2005;62:866-76.

7. Mills A, Akazili J, Ataguba JE, et al. Equity in financing and use of health care in Ghana, South Africa and Tanzania: implications for paths to universal coverage. Lancet. 2012;380:126-33.

8. Akazili J, McIntyre D, Kanmiki EW. Assessing the catastrophic effects of out-of-pocket healthcare payments prior to the uptake of a nationwide health insurance scheme in Ghana. Glob Health Action. 2017;10(1):1-8. 
9. Ichoku EH, Fonta WM. Catastrophic healthcare financing and poverty; empirical evidence from Nigeria. J Soc Econ Dev. 2003;11(2):1-16.

10. World Health Organization. "Global Health Observatory Database, 2018." http://apps.who.int/gho/data/?theme=main.

11. National Statistical Office (NSO) [Malawi] and ICF. Malawi Demographic and Health Survey 2015-16., 2017.

12. National Population Commission (NPC) [Nigeria] and ICF. Nigeria Demographic and Health Survey 2018. Abuja: NPC and ICF; 2019.

13. Ministry of Health, Community Development, Gender, Elderly and Children (MoHCDGEC) [Tanzania Mainland], et al. Tanzania Demographic and Health Survey and Malaria Indicator Survey (TDHS-MIS) 2015-16, 2016

14. Uganda Bureau of Statistics (UBOS) and ICF. Uganda Demographic and Health Survey 2016. Kampala: UBOS and ICF; 2018.

15. Wagstaff A, van Doorslaer E. Catastrophe and impoverishment in paying for health care: With applications to Vietnam 1993-98. Health Econ. 2003;12:921-34.

16. Xu K, Evans DB, Kawabata K, et al. Household catastrophic health expenditures: a multi-country analysis. Lancet. 2003;362:111-7.

17. Kronenberg C, Barros PP. Catastrophic health expendituredrivers and protection: the Portuguese case. Health Policy Plan. 2014;115:44-51.
18. Counts CJ, Skordis-Worrall J. Recognizing the importance of chronic disease in driving healthcare expenditure in Tanzania: analysis of panel data from 1991 to 2010 . Health Policy Plan. 1991;31(2016):434-43.

19. Brinda EM, Andrés RA, Enemark U. Correlates of out-of-pocket and catastrophic health expenditures in Tanzania: Results from a national household survey. BMC Int Health Hum Rights. 2014;14(1):e5.

20. Ataguba JE. Reassessing catastrophic health-care payments with a Nigerian case study. Health Econ Policy Law. 2012;7(3):309-26.

21. Lu C, Liu K, Li L, Yang Y. Sensitivity of measuring the progress in financial risk protection to survey design and its socioeconomic and demographic determinants: a case study in Rwanda. Soc Sci Med. 2017;178:11-8.

22. Masiye F, Kaonga O, Kirigia JM. Does user fee removal policy provide financial protection from catastrophic health care payments? Evidence from Zambia. PLoS One. 2016;11(1):e0146508.

23. Wang W, Temsah G, Carter E. Levels and Determinants of Outof-Pocket Health Expenditures in the Democratic Republic of the Congo, Liberia, Namibia, and Rwanda. DHS Analytical Studies No. 59, 2016 